\title{
Copenhagen, Tartu, world: Gatherings in biosemiotics 2002
}

What is studying life cannot be placeless. The international annual meetings in biosemiotics, as an initiative of the Tartu and Copenhagen biosemiotic groups, started with the first Gatherings held in May 24-27, 2001, in Copenhagen, ${ }^{1}$ and followed by the second Gatherings in June 14-17, 2002, in Tartu. After a decade of numerous biosemiotic sessions under the cover of various bigger meetings either in semiotics or biology, this independent series of symposia intends to be a regular framework for discussions and scholarly exchange of ideas and views in semiotic biology.

The aim of the Gatherings in Biosemiotics is quite ambitious — to work for formation of the biology that would use as a basic approach the methods of semiotics. The importance of this project comes from the understanding that the inclusion of the problems of organic sign processes, including that of the origin of sign, as well as the analysis of meaningful communication in living systems into life science, will require a more general methodology than that of, e.g., biophysics. Thus it can be seen as a paradigm in theoretical biology. Even more - it is a developing of theoretical framework for both semiotics and biology.

The meeting of 2002 included three days of intensive talks and creative discussions in Tartu, a visit to Karl Ernst von Baer House, a session in Puhtu Biological Station (the place of work of Jakob von Uexküll in 1930s), brief walkings on an Estonian wooded meadow and on a raised bog, and the final session in Tallinn Zoo. There were about 40 participants from 15 countries (Kotov, Kull 2002).

The papers were presented by Jesper Hoffmeyer (why the genome is so small), Marcello Barbieri (organic codes ${ }^{2}$ ), Anton Markoš (adressee of the genetic text), Stefan Artmann (Jacobian biopragmatics), Frederik Stjernfelt (the core hypotheses of biosemiotics ${ }^{3}$ ), Kalevi Kull (biosemiosis and intentionality), Wolfgang Hofkirchner (differentia specifica of biosemiosis and a theory of evolutionary systems), Yagmur Denizhan (semiotics and metasystem transition theory), John Collier (information expression and cohesive levels), Claus Emmeche (biosemiotics and experiential biology),

${ }^{1}$ A report on the First Gathering see Emmeche 2001. A collection of papers of the event has been published in Sign Systems Studies vol. 30(1), 2002.

${ }^{2}$ See his paper in the current issue.

${ }^{3}$ See his paper in Sign Systems Studies 30(1): 337-345. 
Tom Ziemke (affordance vs. functional tone: a comparison of Gibson's and Uexküll's theories), Donald Favareau (collapsing the wave function of meaning: the contextualizing resources of talk-in-interaction), Toshiyuki Nakajima (construction of umwelt to control probabilities of events in living), Tommi Vehkavaara (an outline of basic semiotic concepts for bio- and robosemiotics and the emergence of umwelt), Andres Luure (the role of relations in semiotics), Sergey Chebanov (bilateral biosemiotics: a problem of sense on a super-triplet level), Elisabeth Johansson (biosemiotic perspectives in gasflux models), Edwina Taborsky (a pansemiotic architecture), Søren Brier (the third culture), Luis Bruni (the global phenotype), Alexander Sedov (part-whole interactions), Myrdene Anderson (neoteny and its role in taming and domestication), Mette Böll (evolution of empathy), Dominique Lestel (on the expression of negation among animals), Gottfried Suessenbacher (mythology and evolutionary psychology), Aleksei Turovski (semiometabolism of animal associations), Timo Maran (mimicry and mimesis in the biosemiosphere), Mark Vian (biotic integrity, ecosystemic archetypes, and the boundary of self), Morten Tønnessen (umwelt ethics), Tiberiu Mustata (the semiotic substance of homeopathy), Sune Frølund (teleology and the natural history of signification in Hans Jonas), Torsten Rüting (on Jakob von Uexküll archive), and others.

The final session in Tallinn Zoo included an excursion guided by an Estonian zoosemiotician Aleksei Turovski, who described the zoo as a field of reestablishing semiotic boundaries.

The additional information about the event, and information about the past and coming meetings in biosemiotics is available at the web site of the Gatherings in Biosemiotics. ${ }^{4}$ The Gatherings in Biosemiotics 3 will take place in Copenhagen, in July 11-14, 2003. The Fourth Gatherings will be held in Prague, 2004.

In 2002, there have taken place several other biosemiotic meetings too, in addition to the annual gatherings. Among these, let me mention just two.

In May 16-17, 2002, a meeting "Biosemiotik: Praktische Anwendung und Konsequenzen für die Einzeldisziplinen" took place in Jena, in ErnstHaeckel-Hause, as organised by Joachim Schult and his colleagues. The papers were given by K. Kull, J. Schult, M. Schmitt, S. Bradler, J. Hoffmeyer, A. Fürlinger, S. Thiessen, M. Kunert, A. Roepstorff, and S. Artmann.

In June 29-30, 2002, a workshop "Zoosemiotics: from Clever Hans to Kanzi in memory of Tom Sebeok (1920-2001)" took place in San Marino, organised by the International Center for Semiotic and Cognitive Studies as headed by Patricia Violi. The contributors included U. Eco, S. SavageRumbaugh, S. Gozzano, F. Cimatti, and K. Kull).

The context of all these meetings, of course, is influenced by the recent publications. Thus, few words about biosemiotic publications in 2002.

${ }^{4}$ At http:// www.zbi.ee/ uexkull/biosemiotics/. 
First, a new edition of M. Barbieri's Organic Codes (1st, in Italian, 2000; 2nd, in English, 2001) has appeared (Barbieri 2003), and an English edition of A. Markoš' book on hermeneutics of living (Czech edition in 2000, by Vesmir, Prague) has been published (Markoš 2002). Neither of them carry the term 'biosemiotics' in title, however, both books are a remarkable contribution to semiotic biology. Also, D. Martinelli's dissertation (Martinelli 2002) has made an interesting attempt to find further internal connections between zoology and music, in a zoosemiotic context.

The collection of papers from the first Gatherings has been published in volume 30(1) of the journal Sign Systems Studies. In addition to these, among many others, it's worthwhile to mention D. Lestel's (2002) recent paper.

Also, a booklet by Emmeche et al. (2002) needs mentioning. Intended as a Festschrift for a Danish biosemiotician Jesper Hoffmeyer, this book provides also a brief introduction to semiotic biology as approached by TartuCopenhagen group in the field. In the chapter $A$ biosemiotic building: 13 theses, the authors formulate the biosemiotic approach in the form of 13 brief statements. The book includes a glossary of terms and the list of Hoffmeyer's publications.

2002 has been the first year without T. A. Sebeok. Among the thoughts influenced by him and outspoken in the Gatherings of Biosemiotics in 2002, has been this definition - biosemiotics is a biology of sympathy.

\section{References}

Barbieri, Marcello 2003. The Organic Codes: An Introduction to Semantic Biology. Cambridge: Cambridge University Press.

Emmeche, Claus 2001. The emergence of signs of living feeling: Reverberations from the first Gatherings in Biosemiotics. Sign Systems Studies 29(1): 369-376.

Emmeche, Claus; Kull, Kalevi; Stjernfelt, Frederik 2002. Reading Hoffmeyer, Rethinking Biology. (Tartu Semiotics Library 3.) Tartu: Tartu University Press.

Kotov, Kaie; Kull, Kalevi (eds.) 2002. Gatherings in Biosemiotics 2: Abstracts of the Meeting in Estonia (Tartu-Puhtu-Tallinn, June 14-17, 2002). Tartu: University of Tartu.

Lestel, Dominique 2002. The biosemiotics and phylogenesis of culture. Social Science Information 41(1): 35-68.

Markoš, Anton 2002. Readers of the Book of Life: Contextualizing Developmental Evolutionary Biology. Oxford: Oxford University Press.

Martinelli, Dario 2002. How Musical is a Whale: Towards a Theory of Zoomusicology. (Acta Semiotica Fennica 13.) Helsinki: International Semiotics Institute.

Kalevi Kull

5 Author's address: Department of Semiotics, University of Tartu, Tiigi St. 78, 50410 Tartu, Estonia; e-mail: kalevi@zbi.ee. 